risk that they might contain organisms which could prove dangerous to the ecology of the Earth, and it would be advisable first to earry out experiments on theso in closed cology chambers on manned satellites.

The last paper was by Ir. Harlow shapley of the Harvard Observatory, who discussed the probable environment of other planets. He felt sure that there must be many planets in the univorse which would be suitable for life as we know it on Earth (quite apart from the possibility of life in other forms) and it would seem inevitable that some form of life would have evolved on many of them. Whether we can ever communicate with such worlds was another matter. An important factor in the evolution of higher life may be the ozone layer of the Earth's atmosphere (itsolf due indirectly to the photosynthetic production of oxygen by primitive plants) since this layer protects terrestrial organisms from short- wave ultra-violet rays. None of the other planets of our solar system appears to possess such an ozone layer.

In summing-up, Dr. l'arkes discussed the possibility that astronauts might travel for most of their journey in a state of suspended animation, only to be revived when they reached their destination, and recent work on the freezing of whole animals shows that this is not a wholly faneiful suggestion. This also raises the question of whether man would have a useful part to play in the early stages of space travel, or whether it would be better to dovise very elaborate machines to make the observations. The symposium had the excellent result of bringing together workers in many disciplines, and it showed that the remaining difficulties in short-range space flight were mainly engineering problems, whils: those affecting the astronaut himsclf would soon be largely solved.

\title{
INFLUENCE OF CLIMATE ON LIFE
}

$\mathrm{O}$ NE of the most obvious, and at the same time one of the most neglected, statements in the whole field of biology is that all life depends on its environment. Biologists and medical men of the past have made this the basis of much of their thinking, and engineers and architects have often built machines or houses to suit specific climates, but scientific journals still contain reports of biological experiments in which the experimental conditions were neither controlled nor recorded, and buildings or vehicles often fail to display any consideration for local climate. Even the impressive Unesco headquarters completed a few years ago in Paris are liable to cause heat exhaustion in people working there on sunny days, and it is well known that motorcars are the hottest places to he found in many tropical cointries.

At the other extreme, tables of comfortable environmental temperatures usually assume that simple mathematical expressions can be valid in biological processes, and ships ply through some of the climatically most pleasant seas of the world carrying with them the same constant artificial micro-climate which can be found in any office building in New York or London.

The International Society for Bioclimatology and Biometeorology held its second International Bioelimatological Congress recently in London with the avowed intention of improving knowledge about the influence of climate on life by bringing together people active in all parts of the world and in all branches of science whose work is related in some way to these problems. The success of the Congress was considerable, and its effects will probably be folt for some time to come. Some of the work helped to cross-fertilize or to dispel misconceptions by passing ideas and techniques between different specialties or different countries, but much new information of interest was also provided.

Symposia included one on life at high altitudes in which Prof. R. Margaria (University of Milan) related the problem of acclimatization to anoxia with space flying where less oxygen means less pressure which, in turn, means less weight. He also reported the results of experiments which showed that the carotid body chemoreceptors of man were sensitive to oxygen, in any event during anoxia, which was of interest in view of occasional criticisms against conclusions made from such studies on anæsthetized animals. A paper by Prof. A. von Muralt and Dr. W. H. Weihe (University of Berre) reported experiments carried out on the Jungfraujoch at about $11,000 \mathrm{ft}$. and mean barometric pressures of about $500 \mathrm{~mm}$. of mercury which showed that the threshold for various stimuli, such as taste, touch or tendon reflexes, was reduced at high altitudes but returned to normal if oxygen was breathed in. Prof. $R$. Schumacher and Dr. R. Schindler (Hamburg) reported on the 'high-altitude disease' observed at about $16,000 \mathrm{ft}$. in the Andes, where cattle developed heart failure and cedema but recovered quickly after a descent of only about $1,500 \mathrm{ft}$., a condition repro. duced experimentally in rats and observed sometimes in man. It is difficult to escape the conclusion from this that the pressures to be chosen for long journeys into space will not be the lowest to which people at rest can bocome acclimatized but the lowest which will avoid heart failure and oedema.

In a symposium on life in the tropics, Prof. Alrick B. Hertzman (University of St. Louis) suggested, among other things, that correlations between the cardiac output and the skin blood-flow were purely coincidental, as there were situations when one was high and the other low, for example, when the skin is cooled after the whole body has been warmed. However, it could equally be argued that the corre. lations between these are part of a system integrating many variables, which usually works in a given way but in which no single correlation is immutably. fixed, thus conforming to what might be predicter in any complex control system and making the relationship betwoon cardiac output and skin blood. flow somewhat more predictable than a mere coineidonce. Dr. H. Boyko (Israel) showed some impres. sive photographs to illustrate how a patch of desert could be turned in a very short time into a lush garden by applying sound principles of bioclimatology. Dr. J. C. D. Hutchinson (now in Parramatta, Aus- 
tralia, but well remembered from his Cambridge and Edinburgh days) surveyed the problem of domestic cattle in the tropics, especially from the point of selective breeding, and he showed, among other things, how elipping the fur could increase the rate of growth in farm animals, simply by improving heat tolerance. Prof. W. Richards (Bangor) diseussed tropical plants, and he quoted recent evidence from Ibadan and Cambridge that the rapid growth of these plants was related to the favourablo growth of their new leaf. He also quoted some odd rhythrns in equatorial plants, for example, one in singaporo which has a rhythm of 2 years and 8 months, or the Malayan pigeon orchid which flowers quite irregularly though pigeon orchids in any given aroa always flower on the same day.

Prof. C. P. Iuck (Kampala, Uganda) described his studies on elephant, giraffe, rhinoceros and buffalo, which he hunts with cross-bows and suecinyl-cholinimpregnated arrows, so that he can collect sweat, blood and urine, measure body temperatures, or even inoculate animals against diseases, without harm to the animals and, one was glad to hear, with safety to himself. Prof. F. B. Edney (Salisbury, Southern Rhodesia) showed that crabs took increasing amounts of oxygen and survived greater temperatures after acclimatization to heat than before, and that tsetse flies were able to evaporate water from their spiracles, thus avoiding over-heating while engaged in the hard work of sucking bloor in close proximity to a warm animal.

There were many small sessions dealing with more specialized problems. Dr. T. R. A. Davis and Dr. R. J. T. Joy (U.S. Army Research Laboratories, Fort Knox) reported that animals and man exposed to cold for $2 \mathrm{hr}$. daily showed a reduction of shivering after 21-24 days, which was accompanied by an increase of heat production in the muscles without any olectromyographic evidence of shivering. Prof. .). Grayson (Ibadan, Nigeria) produced evidence of similar, apparently purely chemical, heat regulation in the liver, which could also play a part in improved cold tolerance after acclimatization to cold. Related to these findings were those of Prof. H. Hensel and his associates of Marburg, Germany, that cooling of the hypothalamus in animals produced an increase of metabolism in the rest of the body within a few seconds, but more so at lower than at higher environmental temperatures. Taken together, these data probably mean that there may exist a form of true chemical heat regulation not related to shivering, which is probably controlled by the temperature of the hypothalamus, and which can be modified either by thermal impulses from the skin or by a repetition or continuation of the cold stimulus.

Equally interesting was evidence, also from Prol: Hensel, that thermal receptors discharge at a constant level of activity during constant stimulation, so that in the absence of any environmental change the central nervous system receives a constant level of thermal information. In other words, thermal recep. tors would seem to become adapted extremely slowly or not at all. This fits in well with evidence from the Iondon Hospital Medical College that the diminution of sensations and responses to repeated or continued stimuli which plays an important part in acclimatization is a rosult of a central nervous mechanism of habituation and not of any changes in the peripheral receptors.

Other discussions had a wide range, though some did not get beyond defining useful fields for further study. Among these was the problem of air pollution, which appears to be complicated by the fact that certain particles suspended in the air reinforce the action of others. Recognition of one or more potentially harmful substances in the air is therefore insufficient to assess air pollution, and predictions may have to be bassd on a better knowledge of synergistic actions of individual particles.

Difficulties of using scales of environmental comfort were stressed in a very active group on town planning under the chairmanship of Prof. T. K. Page (Sheffield). It appear's that builder's and enginecr's use at least four different comfort scales ; but if one remembers tho effects of habituation on thormal comfort it appears likely that many more comfort, scales would be in use if more people had tried to compute such scales. Evidence was presented also that the provision of warmth is cheaper and easier in cold climates than the provision of eool air in hot places; but this may not always be so, as eivilized communities have studied heating longer than cooling. Evaporating water, where it is available, from the roofs of buildings, as well as the use of solar energy to drive cooling compressors, might lead to simple and cheap ways of avoiding the overheating of buildings or vehicles in hot climates, and considerable improvements may be achieved by good design. Opinions were expressed suggesting that technology may soon romove the need for any physiological adjustments to changes of temperature, but by and large this Congress left the impression that we are still far from the days when uniformly clad people will live at a constant level of thermal acclimatization in one and the same environment anywhere on the Farth and outside it.

F. M. GLaser

\section{COLONIAL DEVELOPMENT AND WELFARE}

\footnotetext{
$\mathrm{T}$ HE schemes made under the Colonial Development and Welfare Act in the period April 1, 1959 , to March 31, 1960, which are detailed in the latest return, bring the total commitments, from April 1, 1946, under the Act to $£ 221,023,632$, of which $£ 18,792,837$ is for research schemos*. The totals for the year in question are $£ 33,001,222$ for

* Colonial Development and Welfare Act. Return of Schemes made and of Loans approved under the Colonial Development and Welfare (London: H.M. Stationery Office, 1960.) $2 s$. 6d. net.
}

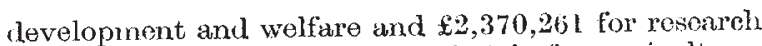

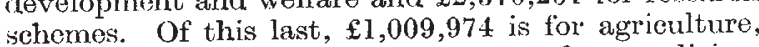

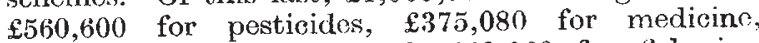
$£ 167,180$ for locust control, $£ 63,860$ for fisheries,

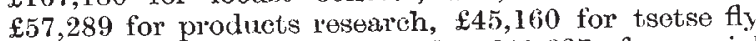
and trypanosomiasis research, $£ 41,697$ for social science, and $\mathfrak{f} 7,796$ for economic research.

Of the actual research schemes, $£ 313,032$ is for the Colonial Pesticides Research Unit, Arusha, Tanganyika, as well as a stpplementary $\mathfrak{f 5 7 , 1 3 9 , 1 9 6 0}$ 